\title{
Targeting Ovarian Cancer Cell Cytotoxic Drug Resistance Phenotype with Xanthium strumarium L. Extract
}

\author{
Marbelis Francisco Fernandez, ${ }^{1}$ Cyndia Charfi, ${ }^{1}$ Janet Piloto-Ferrer, ${ }^{2}$ \\ Maria Lidia González, ${ }^{2}$ Sylvie Lamy, ${ }^{1}$ and Borhane Annabi $\mathbb{D D}^{1}$ \\ ${ }^{1}$ Laboratoire d'Oncologie Moléculaire, Département de Chimie, Centre de Recherche BIOMED, Université du Québec à Montréal, \\ Montreal, Quebec, Canada \\ ${ }^{2}$ Departamento de Genética Toxicológica, Centro de Investigación y Desarrollo de Medicamentos (CIDEM), Avenida 26, \\ No. 1605 e/Puentes Grandes y Boyeros, La Habana, Cuba
}

Correspondence should be addressed to Borhane Annabi; annabi.borhane@uqam.ca

Received 29 May 2019; Accepted 1 October 2019; Published 15 November 2019

Academic Editor: Andresa A. Berretta

Copyright (c) 2019 Marbelis Francisco Fernandez et al. This is an open access article distributed under the Creative Commons Attribution License, which permits unrestricted use, distribution, and reproduction in any medium, provided the original work is properly cited.

\begin{abstract}
Emerging drugs aim at targeting the genomic integrity and replication machinery in ovarian cancer. While the antiproliferative activity of Xanthium strumarium L. extract (XFC), a traditional herbal medicine, is believed to alter the mitotic apparatus of Chinese hamster ovary epithelial cells, its capacity to target and overcome the chemoresistance phenotype in ovarian cancer is unknown. Among the cancer cell lines tested, we found that the best proliferation inhibitory effect for XFC was against ovarian cancer cells and ranged from 30 to $35 \mu \mathrm{g} / \mathrm{mL}$. XFC efficiently targeted both the cytotoxic drug chemoresistance phenotype of SKOV-3 cells and of the chemosensitive ES-2 cells. Early apoptosis and late apoptosis were effectively induced by XFC extract in ES-2 cells, whereas late apoptosis and necrosis events were triggered in SKOV-3 cells. Cell cycling regulation was trapped by XFC extract in the G2/M phase in both the ES-2 and SKOV-3 cell models. This effect was, in part, attributable to increased dosedependent tubulin polymerization, which was increased in SKOV-3 cells. Whereas XFC extract triggered poly (ADP-Ribose) polymerase (PARP) cleavage in both ES-2 and SKOV-3 cells, it only lowered Nrf2 in ES-2 cells and phosphorylated Akt levels in SKOV-3 cells. Interestingly, cell cycling regulators Cdk4, Cyclin D3, and p27 were all decreased in SKOV-3 cells. XFC extracts were effective in inhibiting in vitro migration in both ovarian cancer cell models. Our data support the potential anticancer targeting of chemoresistant human ovarian cancer cells phenotype by XFC extract.
\end{abstract}

\section{Introduction}

Ovarian cancer is the leading cause of gynecological cancer mortality. Despite the fact that first-line chemotherapy is effective in reducing tumor burden following cytoreductive surgery, the 5-year survival rate for stage III and IV disease is $\sim 20-30 \%$ [1]. One of the major reasons for this low survival rate is the onset of drug resistance. Attempts to overcome this resistance to antitumor drugs in ovarian cancer have resulted in the combination chemotherapy of cisplatin (CDDP) and Taxol as the first-line therapeutic protocol via long-term prospective studies of clinical trials [2]. Although many tumor cells in humans gradually acquired resistance during chemotherapy, our understanding of drug resistance mechanisms remains insufficient to overcome clinical failure. Differential molecular and cellular studies using chemoresistant and chemosensitive cell line models can thus serve as an initial screen for agents that can circumvent drug resistance phenotypes.

Resistant cell lines, selected by exposure to antitumor agents, have been valuable tools for the identification of the factors underlying in vitro drug resistance. The use of these resistant cell lines has greatly enhanced our understanding of the mechanisms of resistance and of drug resistance-associated genes, such as multidrug resistance gene 1 (MDR1) and glutathione S-transferase pi (GST-pi) [3, 4]. However, a 
crucial problem is that studies with cells in culture may not always reflect the situation in clinical tumors and contradictory evidence concerning the mechanisms of drug resistance has been reported [5-9]. This situation may be due, at least in part, to differences between the resistant cell lines selected by different approaches and a failure in combination of the laboratory and the clinic.

Throughout history, plants have been the main sources in the discovery of natural-based medicines. In the anticancer area, plant-derived agents such as the Vinca alkaloids, the epipodophyllotoxins, the taxanes, and the camptothecin derivatives are among the most effective cancer chemotherapeutics currently available [10]. The search for new phytochemicals for cancer therapy is therefore a worthwhile endeavor, and the identification of anticancer plant compounds is usually begun by collecting a variety of samples from around the world or by relying on folklore. This is the case for the plant Xanthium strumarium L. (Family: Asteraceae) which exhibits a global distribution and is found abundantly throughout Eurasia and America [11]. Historically, Xanthium species have been used as traditional herbal medicines in oriental countries. They have also been used abundantly as analgesics, as antibacterial and anti-inflammatory agents, and have been used for chronic bronchitis, chronic rhinitis, and allergic rhinitis as well as to relieve constipation, diarrhea, and vomiting [11]. Moreover, plant infusions have been used in the treatment of rheumatism and kidney diseases [12]. It has also been reported that the genus Xanthium is a source for many interesting compounds such as sesquiterpene lactones with xanthanolide-type skeletons that have significant antitumor activity in a variety of cell culture systems [13-16], with terpenoids, thiazolidinediones, sterols, and caffeoylquinic acid as major secondary metabolites. Despite the many studies carried out on Xanthium strumarium L., the cellular and molecular mechanisms underlying the anticancer actions of this plant remain poorly characterized.

In the present study, we induced apoptosis in SKOV-3 cells, an established human epithelial ovarian cancer cell line model resistant both to tumor necrosis factor and to several cytotoxic drugs including diphtheria toxin, cis-platinum, and Adriamycin [8], and compared these with results with established chemosensitive ES-2 ovarian cancer cells. We investigated the effects of Xanthium strumarium L. extract (XFC) administration and assessed its potential to circumvent the drug resistance phenotype in the SKOV-3 chemoresistant ovarian cancer cell model. We provide herein evidence suggesting that the XFC content in anticancer molecules could efficiently target and circumvent the molecular processes that contribute to ovarian cancer cell resistance to current cytotoxic therapies.

\section{Materials and Methods}

2.1. Materials. Sodium dodecyl sulfate (SDS) and bovine serum albumin (BSA) were purchased from Sigma (Oakville, ON). Cell culture media were obtained from Life Technologies (Burlington, ON). Electrophoresis reagents were purchased from Bio-Rad (Mississauga, ON). The enhanced chemiluminescence (ECL) reagents were from Amersham Pharmacia Biotech (Baie d'Urfé, QC). Micro bicinchoninic acid protein assay reagents were from Pierce (Rockford, IL). The monoclonal antibody against GAPDH (glyceraldehyde 3phosphate dehydrogenase) was from Advanced Immunochemical Inc. (Long Beach, CA). The Alexa Fluor ${ }^{\circledR} 488$ donkey anti-rabbit IgG antibody was purchased from Invitrogen (Carlsbad, NM). Polyclonal antibodies against Survivin, Nrf2, AKT, and phospho-AKT, PARP, Cyclin D1, Cyclin D3, Cdk2, Cdk4, Cdk6, and monoclonal antibody against p27 were from Cell Signaling Technology (Beverly, MA).

\subsection{Plant Material and Preparation of Chloroform Extract of} Xanthium strumarium L. (XFC). Xanthium strumarium L. was collected from the Medicinal Plants Experimental Station "Dr. Juan Tomás Roig" in San Antonio de los Baños city (Artemisa, Cuba). A voucher specimen with number ROIG 4594 was deposited at the herbarium of this institution. Plant parts $(500 \mathrm{~g})$ were extracted with $70 \%$ ethanol as described elsewhere [17]. A fluid extract was prepared from the dried material by hydroalcoholic extraction in using four rounds of percolation. It was concentrated under reduced pressure to obtain a raw extract (whole extract). Extraction of chloroform-soluble compounds was described in detail previously [18]. Chloroform was removed by reduced pressure (Büchi Rotavapor), and the residual pale yellow oil was resuspended in dimethyl sulfoxide (DMSO) for the biological evaluations. DMSO (1\% final concentration) served as a negative control condition in all untreated cell conditions. This Xanthium strumarium L. chloroform extract (XFC extract) was used throughout the study to treat cells.

\subsection{Breast, Ovarian, and Colorectal Cancer Cell Cultures.} Human SKOV-3 ovarian adenocarcinoma cells as well as human ES-2 ovarian clear cell carcinoma cells were purchased from the American Type Culture Collection (ATCC). Cells were grown as a monolayer with McCoy's 5a Medium Modified (Wisent, 317-010-CL) containing 10\% fetal bovine serum (Life Technologies, 12483-020), $100 \mathrm{U} / \mathrm{mL}$ penicillin, and $100 \mathrm{mg} / \mathrm{mL}$ streptomycin (Wisent, 450-202-EL). All other cell lines used in the study were from ATCC. MDAMB-231 and MCF-7 (breast cancer cells) as well as HT-29 and $\mathrm{C} 2 \mathrm{BBe}-1$ (colon cancer cells) were grown in Eagle's Minimum Essential Medium (Wisent, 320-036-CL) or in Dulbecco's Modified Eagle's Medium (319-005-CL), respectively, containing 10\% FBS and antibiotics. All the cells were cultured at $37^{\circ} \mathrm{C}$ under a humidified $95 \%-5 \%(\mathrm{v} / \mathrm{v}$ ) mixture of air and $\mathrm{CO}_{2}$.

2.4. Impact of XFC on Cancer Cell Proliferation. The MDAMB-231, MCF-7, ES-2, SKOV-3, HT-29, and C2BBe1 cells were seeded in complete medium $\left(10^{3}\right.$ cells $/ 200 \mu \mathrm{L} /$ well $)$ in 96-well plates, allowed to adhere for 6 hours, and the medium was supplemented with increasing XFC concentrations ranging from 1 to $1000 \mu \mathrm{g} / \mathrm{mL}$ ( $200 \mu \mathrm{L} /$ well, final volume). Cell proliferation was measured after 72 hours 
using the MTT [3-(4,5-dimethylthiazol-2-yl)-2,5-diphenyltetrazolium bromide] cytotoxicity assay in accordance with the protocol described by Mosmann with the following modifications [19]. The cells were incubated with MTT $(0.5 \mathrm{mg} / \mathrm{mL})$ at $37^{\circ} \mathrm{C}$ under a humidified atmosphere containing $5 \% \mathrm{CO}_{2}$ for 4 hours. After incubation, $100 \mu \mathrm{L}$ DMSO (solubilizing reagent) was added to each well and mixed thoroughly to dissolve the dark blue crystals. The presence of viable cells was visualized by the development of a purple color due to the formation of formazan crystals. The plates were read on a SpectraMax Plus reader (Molecular Devices, Sunnyvale, CA) using a test wavelength of $570 \mathrm{~nm}$ and reference wavelength of $630 \mathrm{~nm}$. The $\mathrm{IC}_{50}$ values of the samples were determined from a dose-response curve obtained by using seven different sample concentrations (6.25, $12.5,25,50,100,200$, and $400 \mu \mathrm{g} / \mathrm{mL}$ ). Analyses were made in triplicate for each condition.

2.5. Apoptosis Analysis. Apoptosis was determined by FITClabeled Annexin V/PI double staining and flow cytometry analysis. Briefly, SKOV-3 and ES-2 cells were treated with XFC at $12.5,25,50,100,200$, and $400 \mu \mathrm{g} / \mathrm{mL}$ for 24 or 48 hours. At the indicated time, cells were harvested and fixed, and apoptosis was then measured using the FITC Annexin V Apoptosis Detection Kit II (BD Biosciences, Mississauga, $\mathrm{ON}$ ) according to the manufacturer's protocol. The percentages of cells within early and late stages of apoptosis were determined using a BD Accuri C6 flow cytometer. The data were analyzed using FlowJo 10.1 software. At least 10,000 cells were counted for each measurement. The following controls were used to set up gates: unstained cells, cells with FITC Annexin V only, and cells with PI only.

2.6. Cell Cycle Analysis. ES-2 and SKOV-3 cells were incubated for 48 hours in medium without $\mathrm{FBS}$ at $37^{\circ} \mathrm{C}$ in $5 \%$ $\mathrm{CO}_{2}$ for synchronization of the cell cycle. Cells were then treated for 24 hours with either $0.1 \%$ DMSO (controls) or various concentrations of XFC $(20,30,40,50$, or $60 \mu \mathrm{g} / \mathrm{mL})$. Treatments were performed in medium containing $10 \%$ FBS. At the end of treatment, the cells were collected by mild trypsin digestion, washed with ice-cold PBS, and fixed in icecold $70 \%$ ethanol in PBS overnight at $-20^{\circ} \mathrm{C}$. Cells were then centrifuged at $10,000 \mathrm{rpm}$ for $10 \mathrm{~min}$, followed by careful removal of the supernatant. Three volumes of staining solution in PBS, containing propidium iodide (PI, $40 \mu \mathrm{g} / \mathrm{mL}$; Calbiochem, San Diego, CA) and DNase-free RNase (100 $\mu \mathrm{g} /$ $\mathrm{mL}$ ), were added for at least $30 \mathrm{~min}$ at $37^{\circ} \mathrm{C}$ in the dark before analysis. The proportion of the cell population in each phase of the cell cycle was determined as a function of the DNA content using a BD Accuri C6 flow cytometer (BD Biosciences, Mississauga, ON). Cell cycle analysis was performed with the BD AccuriTM C6 software (version 1.0.264.21). For each measurement, at least 10,000 cells were counted.

2.7. Immunofluorescence Staining of Tubulin Cytoskeleton. ES-2 and SKOV-3 cells were seeded on cover slips and treated with the indicated concentrations of XFC or with nocodazole $(50 \mathrm{ng} / \mathrm{mL})$ for 24 hours. Cells were rinsed in PHEM buffer (60 mM PIPES, 25 mM Hepes, 10 mM EGTA, $2 \mathrm{mM} \mathrm{MgCl} 2$ ), fixed in $4 \%$ formaldehyde for $15 \mathrm{~min}$ at room temperature and permeabilized with $0.5 \%$ Triton X-100 for $5 \mathrm{~min}$. After the reaction was blocked in 10\% BSA/PBS, the cells were incubated with mouse anti- $\alpha$-tubulin antibody (1/ 2,000; T5168; Sigma) for 1 hour at room temperature. After several washes, the cells were incubated with Alexa Fluor488 conjugated anti-rabbit IgG antibody (1/1,000 dilution) for 1 hour at room temperature. The cell nuclei were visualized with $1 \mu \mathrm{g} / \mathrm{mL}$ DAPI staining for $5 \mathrm{~min}$. Slides were then dried and mounted with the ProLong Gold antifade reagent (Fisher Scientific, Ottawa, ON). The cells were visualized with an A1R Nikon confocal unit attached to an inverted Eclipse Ti microscope using a Plan Apo 60/1.4 NA oil objective (Nikon Canada, Mississauga, ON). The resulting micrographs were acquired and processed with NIS Element (Nikon Canada) and ImageJ (U.S. National Institutes of Health, Bethesda, MD) software packages.

2.8. Immunoblotting Assessment of PARP Cleavage and of Cell Cycle Regulators. Proteins from control and treated cells were separated by SDS-polyacrylamide gel electrophoresis (PAGE). After electrophoresis, proteins were electrotransferred to polyvinylidene difluoride membranes which were then blocked for 1 hour at room temperature with 5\% nonfat dry milk in Tris-buffered saline $(150 \mathrm{mM} \mathrm{NaCl}$, $20 \mathrm{mM}$ Tris-HCl, $\mathrm{pH}$ 7.5) containing $0.3 \%$ Tween-20 (TBST). Membranes were further washed in TBST and incubated with the primary antibodies (1/1,000 dilution) in TBST containing $3 \%$ BSA, followed by a 1-hour incubation with horseradish peroxidase-conjugated anti-rabbit IgG (1/ 2,500 dilution) in TBST containing $5 \%$ nonfat dry milk. Immunoreactive material was visualized with the ECL detection system. The immunoreactive bands were quantified using ImageJ software (NIH).

2.9. Wound-Healing Assay. ES-2 and SKOV-3 cells were seeded into 6-well tissue culture dishes and grown to nearly confluent cell monolayers. Then, a linear wound was generated in the monolayer with a sterile $200 \mu \mathrm{L}$ pipette tip creating a cell-free area [20]. Cultures were gently washed with the growth medium to remove loose cells. The cells were then treated with either vehicle or XFC $(60 \mu \mathrm{g} / \mathrm{mL})$ in culture medium supplemented with $1 \%$ FBS. Cells for control conditions were also scratched, washed, and maintained in culture medium supplemented with 1\% FBS after the scratch. Immediately after the scratch and at 4, 8, and $24 \mathrm{~h}$, at least four images of the scraped area were captured using phase contrast microscopy and analyzed using ImageJ software. Two independent experiments were performed, using three wells for each stimulating condition. The same scratched area was selected for the measurements at each time of the study.

2.10. Statistical Data Analysis. Data are representative of three or more independent experiments. Statistical 
significance was assessed using Student's unpaired $t$-test and was used to compare the XFC effect to vehicle-treated cells. All statistical analyses and graphs were performed using the GraphPad Prism software version 5.0b (San Diego, CA). Where indicated, data were presented as means \pm SD of three independent experiments (significance: ${ }^{*} p<0.05$, ${ }^{* *} p<0.01,{ }^{* * *} p<0.001$ versus the negative control).

\section{Results}

3.1. Impact of the Xanthium strumarium L. Extract (XFC) on Breast, Ovarian, and Colorectal Cancer Cells Proliferation. The antiproliferative capacity of XFC was first assessed on established human cancer cell models derived from breast adenocarcinomas (MCF-7, MDA-MB-231), from colorectal adenocarcinomas (HT-29, C2BBe-1), from ovarian clear cell carcinoma (ES-2), or from ovarian adenocarcinoma (SKOV3). XFC was able to dose-dependently inhibit cell proliferation (Figure 1(a)), with the greatest inhibition potential observed against the two ovarian cancer cell models where $\mathrm{IC}_{50}$ values ranged from 30 to $35 \mu \mathrm{g} / \mathrm{mL}$ (Figure $1(\mathrm{~b})$ ). This suggests that XFC possesses the ability to inhibit cancer cell proliferation, with the strongest effect against ovarian cancer cells.

3.2. XFC Triggers Late Apoptosis in ES-2 Ovarian Cancer Cells. Whether XFC triggered any proapoptotic events was next assessed after 24 and 48 hours of XFC treatment by flow cytometry (Figures 2(a) and 3(a)). We found that early apoptosis and late apoptosis were effectively induced by XFC in ES-2 cells and increased with time (Figure 2(b)), whereas late apoptosis and necrosis events were triggered in SKOV-3 cells (Figure 3(b)). XFC can therefore efficiently target the effective cytotoxic drug chemoresistance phenotype reported for SKOV-3 as well as the chemosensitive ES-2 cells.

3.3. XFC Alters ES-2 and SKOV-3 Cell Cycle Division. Given its antiproliferative and proapoptotic effects, we next addressed how XFC could alter cell cycle division by assessing sub-G1, G0/G1, S, and G2/M phases (Figure $4(\mathrm{a})$ ). Cells were trapped in the $\mathrm{G} 2 / \mathrm{M}$ phase upon XFC treatment of both ES-2 and SKOV-3 cell models (Figure 4(b), red bars). This again suggests that XFC can significantly alter molecular events regulating cell division processes controlling cell proliferation.

3.4. XFC Alters Tubulin Cytoskeleton in SKOV-3 Ovarian Cancer Cells. Increased tubulin levels and decreased polymerization ratio are hallmarks of resistant cells [21]. Here, we tested whether the antimitotic activity of XFC extract altered tubulin polymerization [22] in human ovarian cancer cells, and this was compared to the microtubules depolymerizing agent Nocodazole [23]. We found that XFC altered microtubules organization (Figures $5(\mathrm{a})$ and $5(\mathrm{~b})$ ) as it increased tubulin polymerization in SKOV-3 cells as compared to ES-2 cells (Figure 5(c)). By examining the morphologies of microtubules and chromosomes, we found increased multipolar mitotic spindles consequent to the aggregation of asters as well as increased monopolar spindles consequent to nonseparated centrioles in both cells treated with XFC. In agreement with this, the chromosomes remained condensed but were not able to align properly, which can be explained by the formation of the multipolar acentrosomal spindle leading to a failure of chromosomal segregation. In addition, treated cells that were able to eventually exit mitosis showed aberrations associated with abnormal karyokinesis (increased frequency of cells bearing micronuclei) and failure of cytokinesis (increase in cells containing multiple nuclei) (Figures 5(a) and 5(b)). Such phenomena are typical outcomes of antimitosis drugs. Taken together, these data indicate that XFC directly affects mitosis progression by disrupting the assembly of the normal mitotic spindle.

3.5. XFC Signals PARP Cleavage in SKOV-3 Ovarian Cancer Cells. Different levels of alterations in apoptotic versus necrotic cell death balance as well as in cell cycling prompted us to investigate whether several intracellular stress biomarkers were also altered (Figure 6(a)). Interestingly, a transient increase in Survivin expression was observed in ES2 cells whereas it remained unchanged in SKOV-3 cells, suggesting that the latter cell model did not require Survivin to resist the XFC stress induction. However, the global phosphorylation status of Akt decreased in ES-2 cells and even more significantly in SKOV-3 cells (Figure 6(b)). Expression of the nuclear factor erythroid 2-related factor 2 (Nrf2), an emerging regulator of cellular resistance to oxidants [24] believed to control the expression of antioxidant response element- (ARE-) dependent genes which regulate cellular resistance to oxidants [25], was found to decrease in XFC-treated ES- 2 cells but not in SKOV-3 cells. This confirmed the chemoresistance phenotype of SKOV-3 cells. Finally, cleaved PARP immunoreactive material was significantly induced in ES-2 cells but was also induced in SKOV-3 cells. Altogether, this confirms the high drug resistance phenotype of SKOV-3 cells to cytotoxics as compared to the chemosensitive ES-2 cells. Nevertheless, our data still support some aspects of the cytotoxic properties of $\mathrm{XFC}$ that can circumvent this resistance phenotype.

3.6. XFC Alters Cell Cycle Regulators in SKOV-3 Ovarian Cancer Cells. A common mechanism of cell cycle arrest involves the upregulation of endogenous Cdk inhibitors, including $\mathrm{p} 27^{\mathrm{Kip} 1}$ and $\mathrm{p} 21$, which prevent cell cycle progression by blocking Cdk activity [26]. Immunoblotting indicated that $\mathrm{p} 27^{\mathrm{Kip} 1}$ levels did significantly increase in ES-2 cells (Figure 7(a)), whereas they significantly decreased in chemoresistant SKOV-3 cells (Figure 7(b)). When Cdk2, Cdk4, and Cdk6 expression levels were assessed, that of Cdk2 decreased significantly in ES-2 cells upon XFC treatment, whereas it was less altered in SKOV-3 cells (Figure 7(b)). Whereas Cdk6 only increased in ES-2 cells, Cdk 4 in contrast decreased upon XFC treatment in SKOV-3 cells but remained unchanged in ES-2 cells (Figure 7(b)). Protein levels of Cyclin D1 in ES-2 cells were decreased 

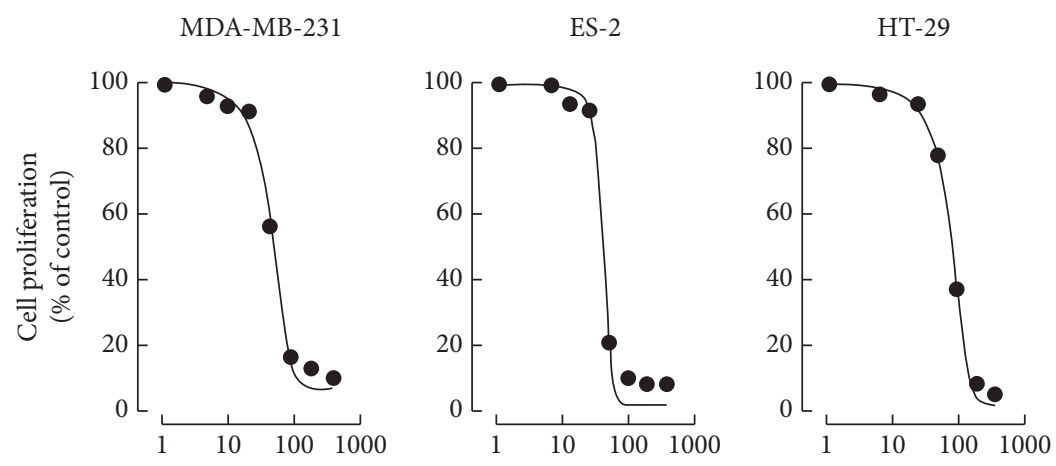

\begin{tabular}{lcc}
\hline $\begin{array}{l}\text { Human cancer } \\
\text { cell line }\end{array}$ & Histology & $\begin{array}{c}\mathrm{IC}_{50} \\
(\mu \mathrm{g} / \mathrm{ml})\end{array}$ \\
\hline HT-29 & $\begin{array}{c}\text { Colorectal } \\
\text { adenocarcinoma }\end{array}$ & $78.6 \pm 4.7$ \\
C2BBe -1 & $\begin{array}{c}\text { Colorectal } \\
\text { adenocarcinoma }\end{array}$ & $45.4 \pm 9.8$ \\
MDA-MB-231 & $\begin{array}{c}\text { Breast } \\
\text { adenocarcinoma }\end{array}$ & $51.0 \pm 4.5$ \\
MCF-7 & $\begin{array}{c}\text { Breast } \\
\text { adenocarcinoma }\end{array}$ & $40.6 \pm 8.0$ \\
ES-2 & $\begin{array}{c}\text { Ovarian clear } \\
\text { cell carcinoma }\end{array}$ & $30.4 \pm 3.0$ \\
SKOV-3 & $\begin{array}{c}\text { Ovarian } \\
\text { adenocarcinoma }\end{array}$ & $35.2 \pm 4.8$ \\
\hline
\end{tabular}
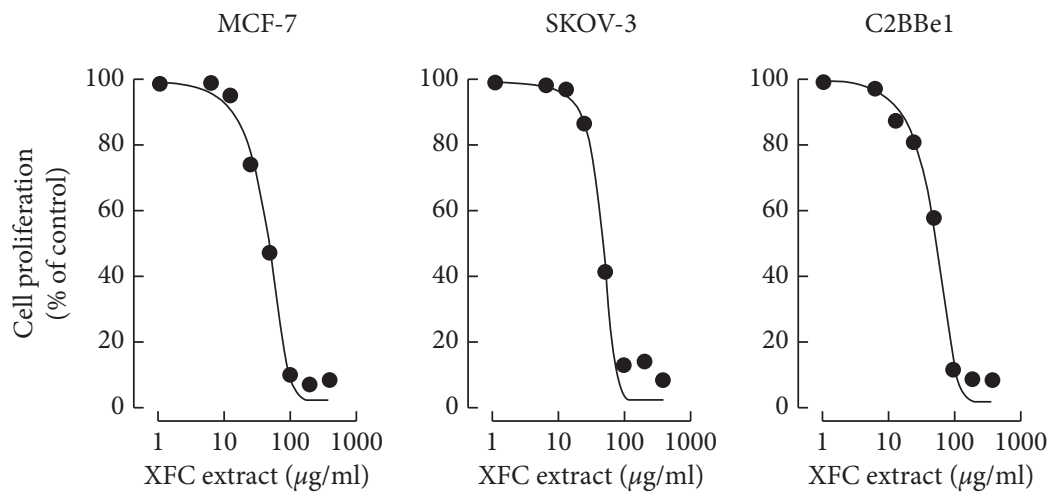

(a)

(b)

Figure 1: Impact of the Xanthium strumarium L. extract (XFC) on breast, ovarian, and colorectal cancer cells proliferation. Mid-log phase human cancer cell models derived from breast adenocarcinomas (MCF-7, MDA-MB-231), colorectal adenocarcinomas (HT-29, C2BBe-1), ovarian clear cell carcinoma (ES-2), and ovarian adenocarcinoma (SKOV-3) were seeded in 96-well plates at $10^{3}$ cells/well density in $200 \mu \mathrm{L}$ medium and cultured as described in Section 2. Cells were then (a) treated with various concentrations of XFC for 72 hours and then incubated with MTT $(0.5 \mathrm{mg} / \mathrm{mL})$ for 4 hours in order to quantify cell proliferation (a representative curve is shown for each cell line). (b) $\mathrm{IC}_{50}$ values were obtained for cell line treatments, which were performed in triplicate.

drastically by XFC treatment, whereas they remained unchanged in SKOV-3 cells (Figure 7(b)). Cyclin D3 expression was significantly downregulated in both SKOV-3 and ES-2 cells.

3.7. SKOV-3 Ovarian Cancer Cells Cannot Reverse the Impact of XFC in a Wound-Healing Assay. The effect of XFC on the ability of cells to migrate in response to a wound was next assessed (Figure 8(a)). While ES-2 cells were able to partly rescue wounding, XFC treatment in SKOV-3 cells prevented migration of the wound region (Figure $8(\mathrm{~b})$ ). This property suggests that XFC can halt SKOV-3 cell migration.

\section{Discussion}

Although ovarian cancer is the most deadly gynecologic malignancy worldwide, chemotherapy remains the mainstay treatment. Although the initial response to this treatment is generally promising, frequent recurrence in patients with advanced stages of the disease remains a therapeutic challenge. Thus, understanding the biology of chemoresistance is of great importance for overcoming this challenge and should benefit the survival of ovarian cancer patients. Although complex mechanisms underlie the development of ovarian cancer chemoresistance, here we show that XFC may significantly alter cell survival properties associated with this resistance phenotype in a cytotoxic, drug-resistant SKOV-3 ovarian cancer cell model. Importantly, SKOV-3 cells are documented to be resistant to tumor necrosis factor and to several cytotoxic drugs including diphtheria toxin, cis-platinum, and Adriamycin where efflux in drug accumulation was assessed in vitro against four platinum complexes, and where decreased drug accumulation reported to be in part responsible for acquired resistance to cisplatin [27].

In this study, it is demonstrated that XFC exhibited antiproliferative activity against several cell line models of breast, ovarian, and colon cancer. We found that the percentage of growth inhibition was dose-dependent with the best XFC antiproliferative effect against ovarian chemosensitive ES-2 and chemoresistant SKOV-3 cancer cells. While the two breast cancer cell and two colon cancer cell models tested herein were also found responsive to XFC treatment to some extent, their lower responsiveness may suggest that specific targeting and efficient pharmacological effects are conditioned by the differential molecular and cellular signature of a given cancer. This further prompts for future identification of the exact cell surface and/or intracellular biomarkers specifically involved in the actions of 

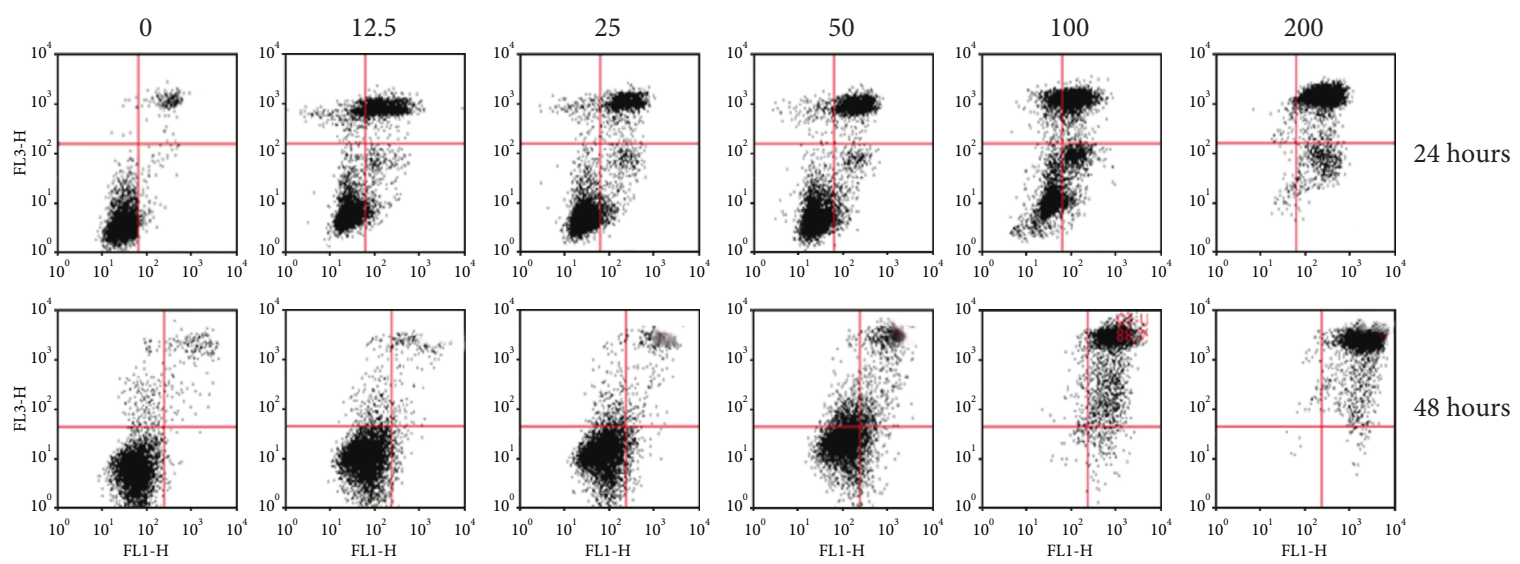

(a)
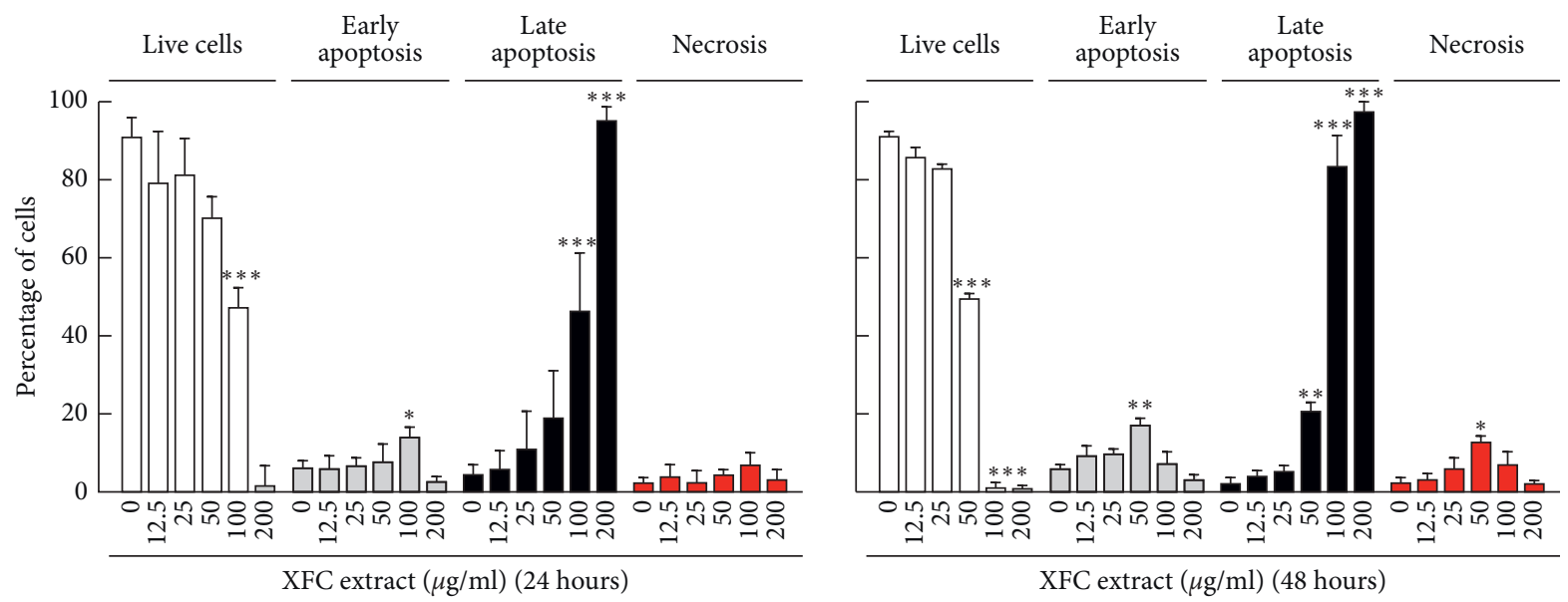

(b)

FIGURE 2: XFC triggers late apoptosis in ES-2 ovarian cancer cells. Human ovarian clear cell carcinoma cells (ES-2) were cultured and treated with increasing concentrations of XFC in serum-free media for 24 or 48 hours, followed by fixation, PI staining, and (a) data acquisition by flow cytometry as described in Section 2 to assess cell death phases. (b) Data analysis was also performed as described in Section 2 in order to assess levels of live cells, early apoptosis, late apoptosis, and necrosis.
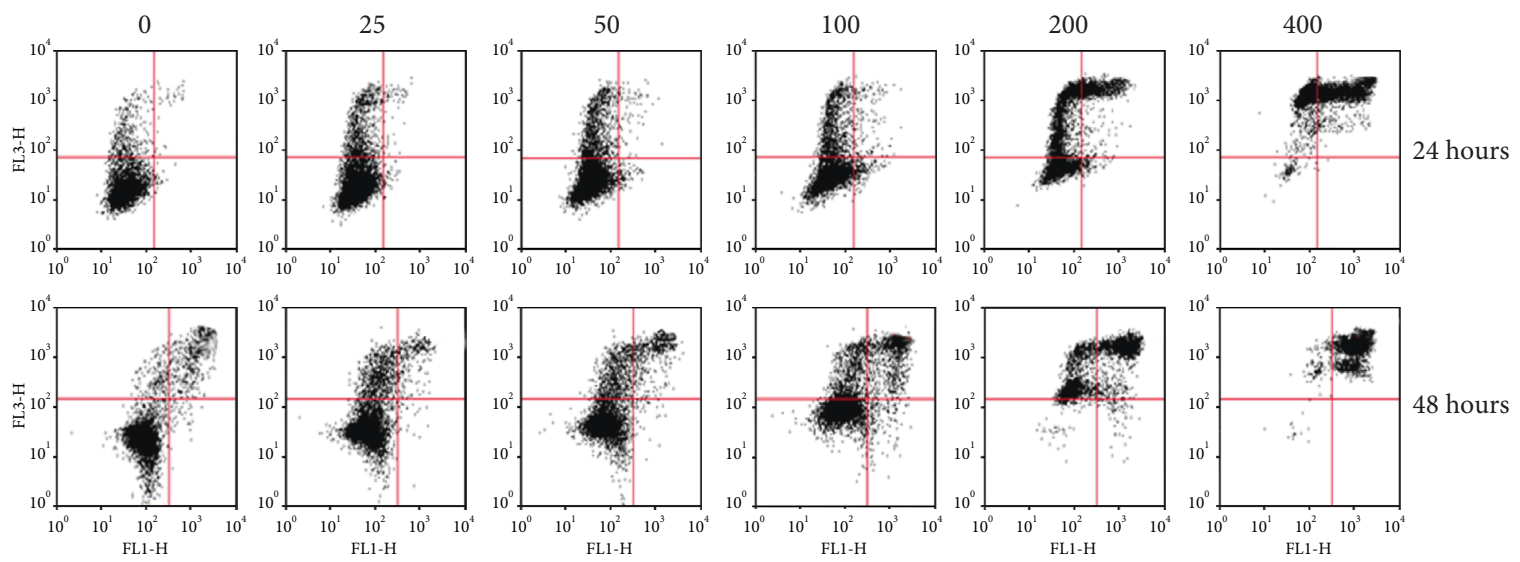

(a)

Figure 3: Continued. 

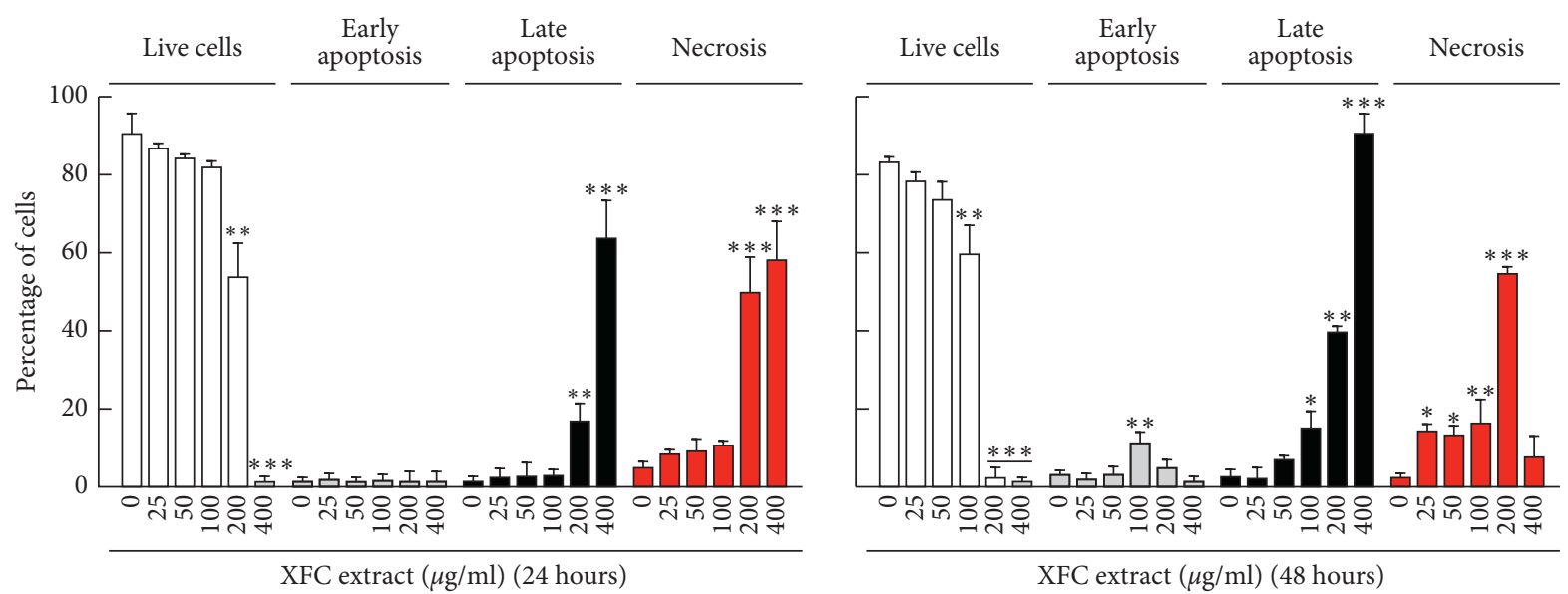

(b)

FIGURE 3: XFC triggers late apoptosis and necrosis in SKOV-3 ovarian cancer cells. Human ovarian adenocarcinoma (SKOV-3) cells were cultured as described in Section 2. Treatment with various concentrations of XFC was performed in serum-free media for 24 or 48 hours, followed by fixation, PI staining, and (a) data acquisition by flow cytometry, as described in Section 2 to assess cell death phases. (b) Data analysis was also performed as described in Section 2 in order to assess levels of live cells, early apoptosis, late apoptosis, and necrosis stages.
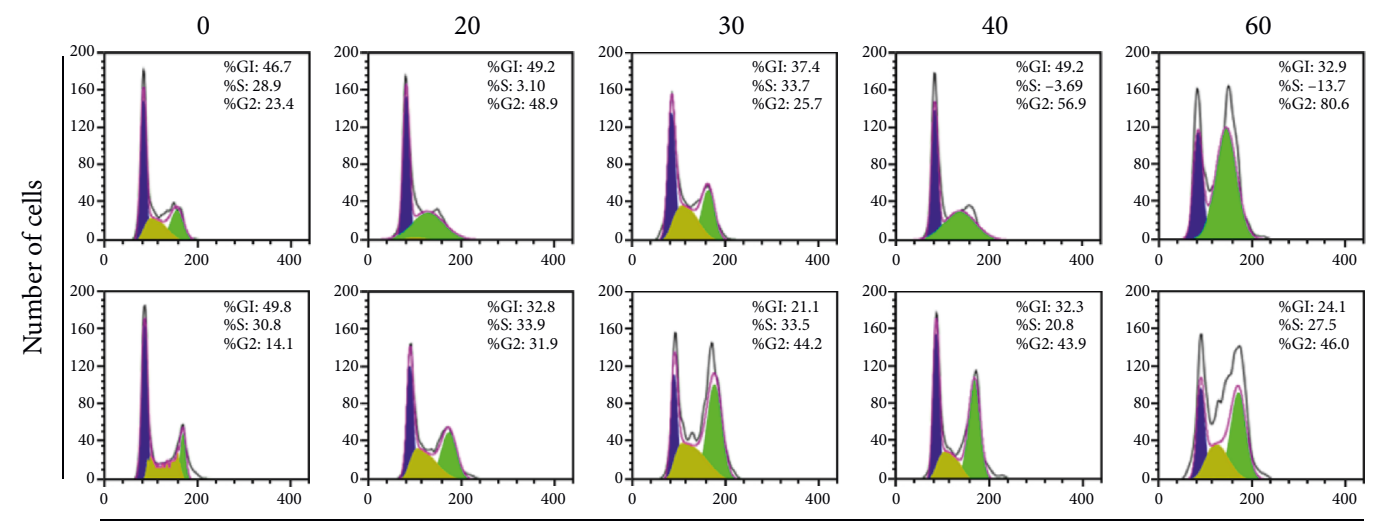

ES-2

DNA content

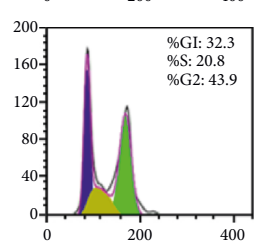

SKOV-3

(a)

ES-2

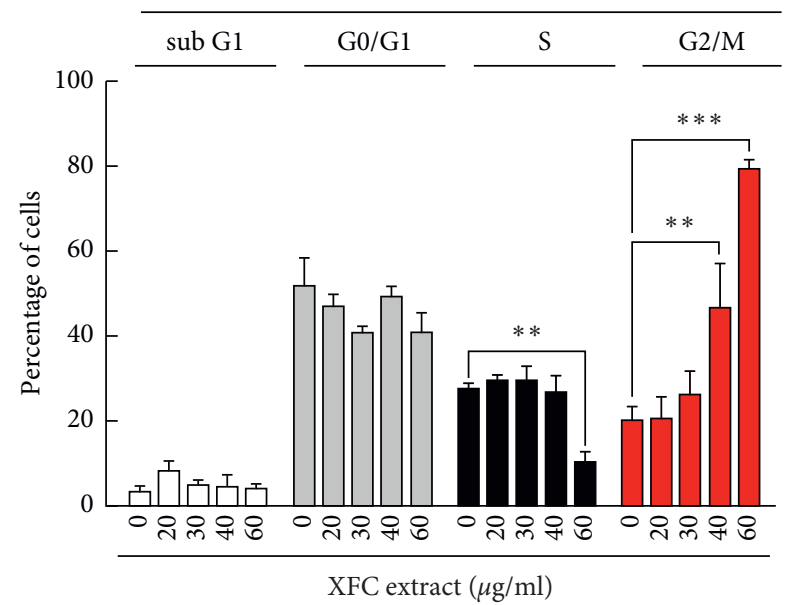

SKOV-3

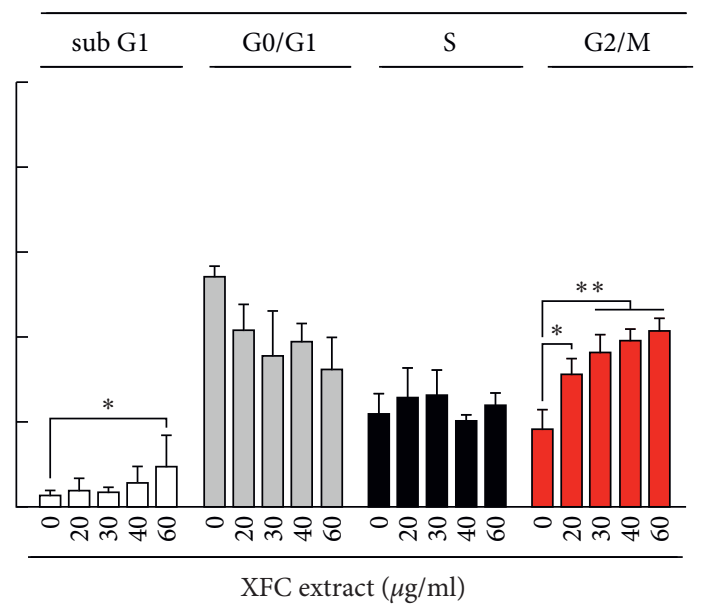

(b)

FIGURE 4: XFC extract alters ES-2 and SKOV-3 cell cycle division. Human ovarian clear cell carcinoma (ES-2) and human ovarian adenocarcinoma (SKOV-3) cells were cultured, followed by treatments with various concentrations of XFC in serum-free media for 24 hours, fixation, and by PI staining. (a) Data acquisition was performed by flow cytometry as described in Section 2 in order to assess cell cycle phases. (b) Data analysis was also performed in order to assess the levels of cells in sub-G1, G0/G1, S, and G2/M phases. Significance: ${ }^{*} p<0.05,{ }^{* *} p<0.01,{ }^{* * *} p<0.001$ versus the negative control. 


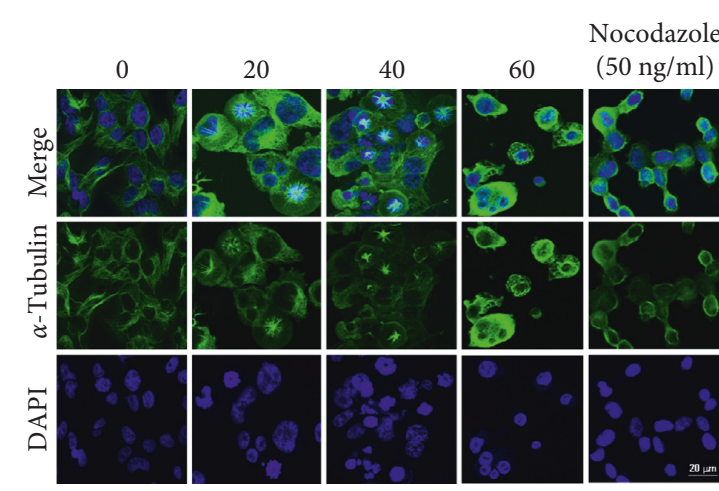

(a)

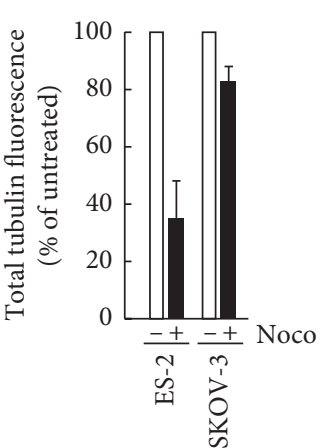

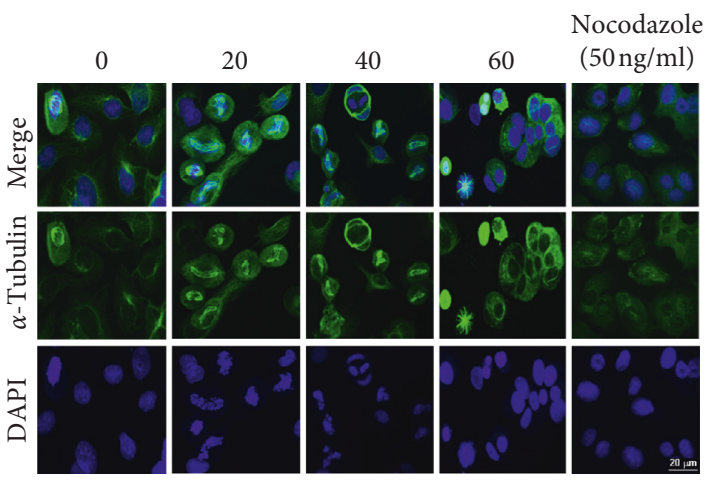

(b)

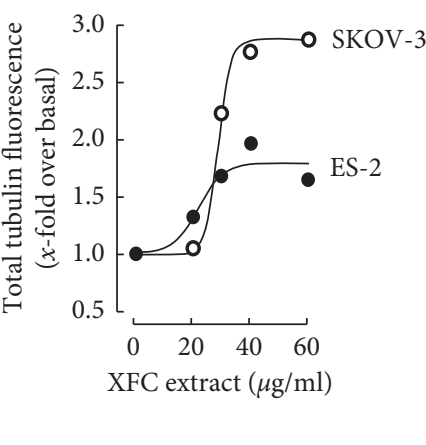

(c)

FIGURE 5: Preferential alteration of the tubulin cytoskeleton in the SKOV-3 ovarian cancer cells by XFC. Human ovarian clear cell carcinoma (ES-2) and human ovarian adenocarcinoma (SKOV-3) cells were cultured as described in Section 2. Treatment with various concentrations of XFC or with nocodazole was performed in serum-free media for 24 hours. Immunostaining of tubulin was performed with antitubulin antibody. DAPI was used as a nuclear stain. Fluorescence microscopy was used for data acquisition in (a) ES-2 and (b) SKOV-3 ovarian cancer cells. (c) Total fluorescence was acquired and the data was processed as described in Section 2.

the active molecules within XFC. As such, it has been reported that XFC contains 3,4-dihydroxybenzaldehyde that inhibits human U937 cancer cells [28]. Two xanthanolide sesquiterpene lactones, 8 -epi-xanthatin and 8-epixanthatin- $5 \beta$-epoxide, have also been isolated from leaves and inhibit different cancer cell lines such as A549 (lung), SK-MEL-2 (melanoma), XF498 (CNS), and HCT-15 (colon) [13]. Whether these isolated molecules also alter ES-2 and SKOV-3 cell lines requires further examination although traditional medicinal research emphasises that the mixture of herbal extracts usually has lower toxicity and higher efficacy than individual molecules [29]. For instance, the crude extract of Rabdosia rubescens has shown higher synergistic effects at several concentrations than do its individual active ingredients. Furthermore, the total phenolic extract of blueberry was also found to significantly inhibit the growth of several oral (CAL27 and KB) and prostate (22RV1, RWPE-2, and RWPE-1) cancer cell lines [30]. As reported previously, the impact of XFC treatment is therefore not just related to one specific chemical compound, but it is the synergistic actions of different compounds that provide such an inhibitory effect [31]. According to the National Cancer Institute (NCI, USA) criteria, a crude extract would be considered as cytotoxic when an $\mathrm{IC}_{50}<20 \mu \mathrm{g} / \mathrm{mL}$ [32]. While the current $\mathrm{IC}_{50}$ $(\sim 30-35 \mu \mathrm{g} / \mathrm{mL})$ of the XFC extract appears slightly higher, further fractionation will be required to identify the active component(s) that may alone or in synergy further represent promising candidates for anticancer drug $\mathrm{R} \& \mathrm{D}$. However, such fractionation of XFC may result in the loss of its integrity and potential therapeutic potential. This further justifies the use of total extracts in the treatment of various diseases.

Natural or synthetic antimitotic molecules represent a considerable potential source for anticancer drugs because tumor cells are characterized by high mitotic activity as compared to normal cells. As such, antimitotic drugs have proven very effective against a wide range of tumors [33]. In response to induced mitotic spindle disturbances, cells are arrested in mitosis and, after prolonged mitotic arrest, undergo apoptosis, a feature of the anticancer effects elicited by these drugs [33-35]. Our study demonstrates that XFC selectively induces mitotic arrest in ES- 2 and SKOV-3 cells, leading to decreased cell growth and viability in a dose- and time-dependent manner (Figure 4). XFC also inhibited normal mitotic progression by interfering with the metaphase to anaphase transition, consistent with previous data showing an antitubulin action of the extract $[8,17]$. Our data, showing an impairment in anaphase entrance, demonstrates that XFC interferes with the normal function of the mitotic spindle, effects similar to those displayed by other well-known antimitotic drugs [36]. 

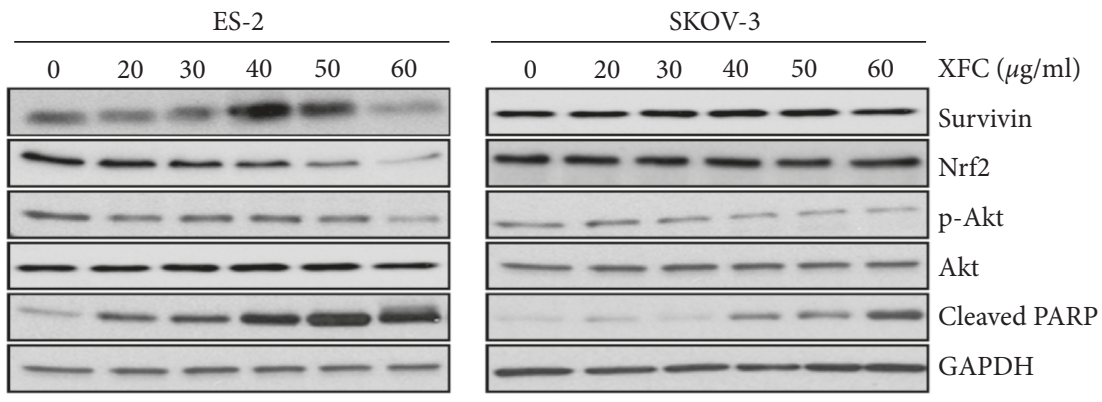

(a)
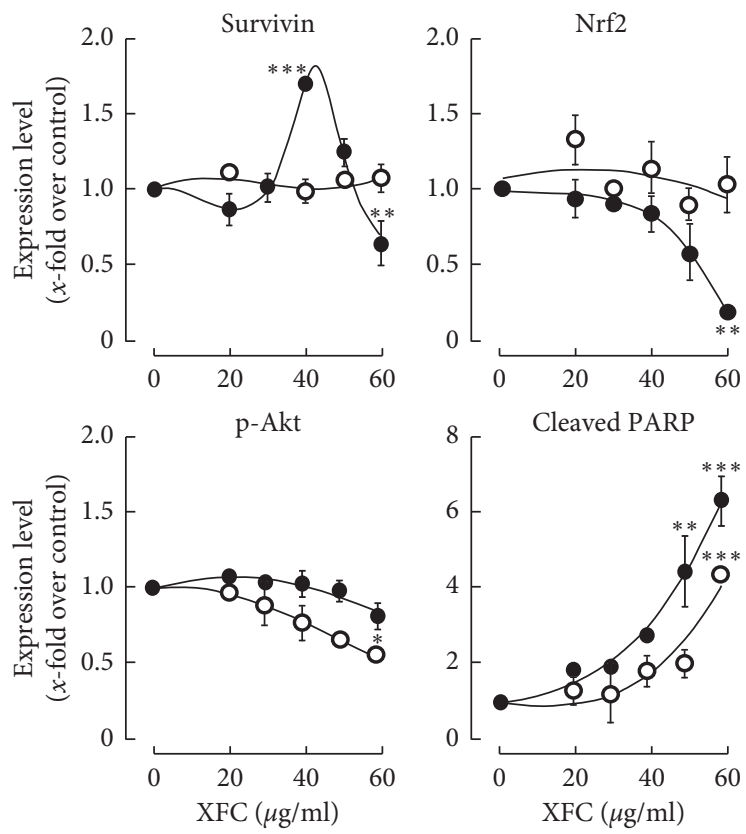

- ES-2

O SKOV-3

(b)

FIgURE 6: XFC extract triggers PARP cleavage in SKOV-3 ovarian cancer cells. Human ovarian clear cell carcinoma (ES-2) and human ovarian adenocarcinoma (SKOV-3) cells were cultured as described in Section 2. Treatment with various concentrations of XFC was performed in serum-free media for 24 hours. Cell lysates were harvested and then processed for (a) SDS-PAGE and Western blotting in order to assess the phosphorylation status of Akt, expression levels of Survivin, Nrf2, GAPDH, and cleaved PARP. (b) Levels of expression were quantified using scanning densitometry.
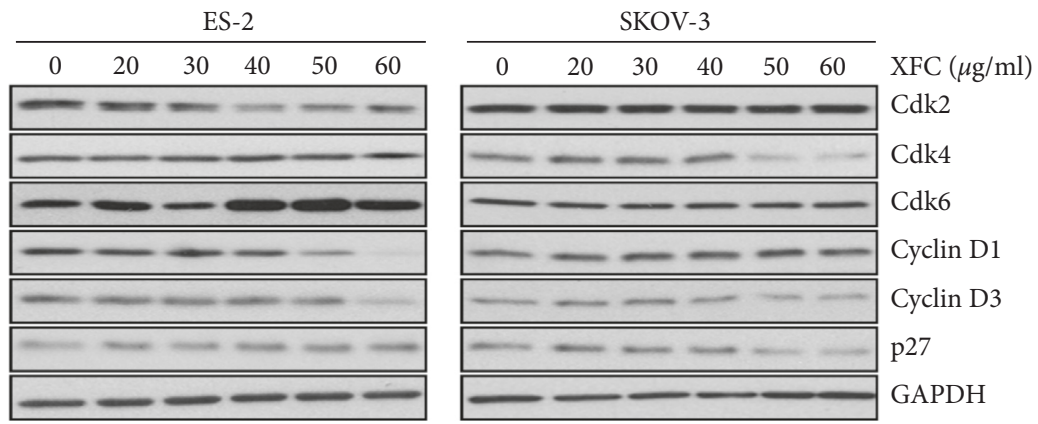

(a)

Figure 7: Continued. 
Cdk2
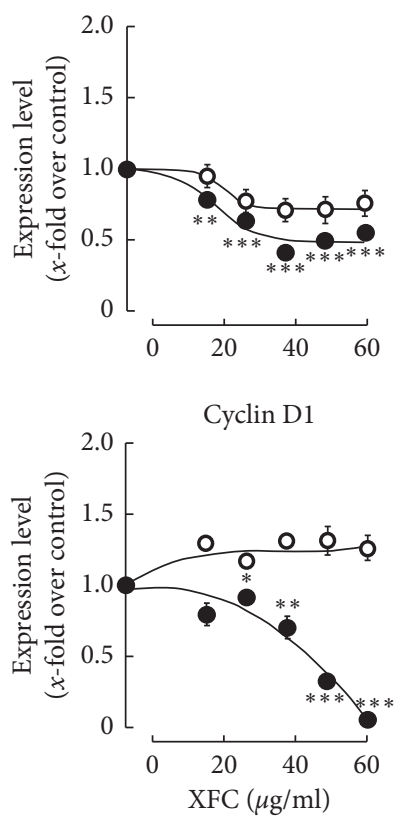

- ES-2
Cdk4
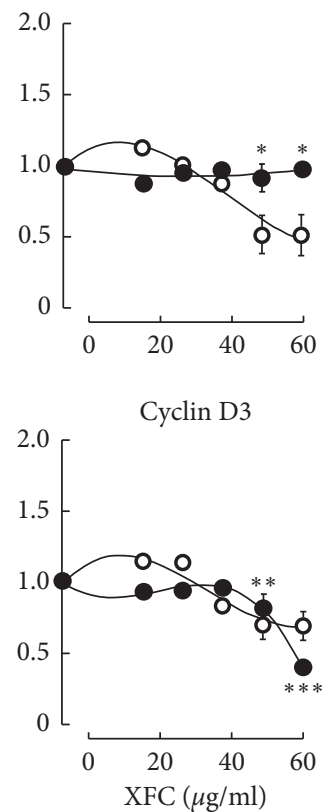

Cdk6
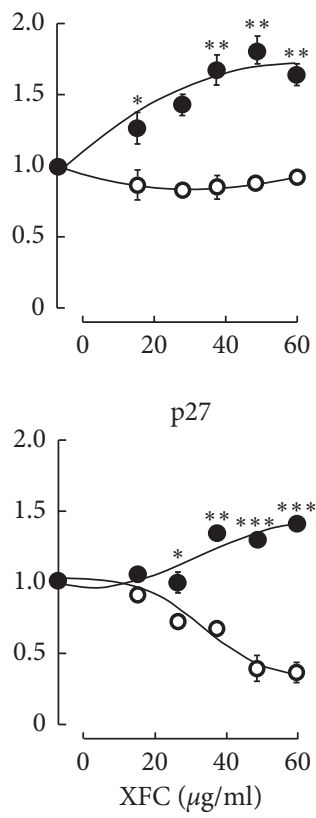

o SKOV-3

(b)

FIGURE 7: XFC extract inhibits CDK4 and cyclin D3 in SKOV-3 ovarian cancer cells. Human ovarian clear cell carcinoma (ES-2) and human ovarian adenocarcinoma (SKOV-3) cells were cultured as described in Section 2. Treatment with various concentrations of XFC was performed in serum-free media for 24 hours. Cell lysates were harvested and then processed for (a) SDS-PAGE and western blotting in order to assess the expression levels of Cdk2, CDk4, Cdk6, Cyclin D1, Cyclin D3, p27, and GAPDH. (b) Levels of expression were quantified using scanning densitometry.
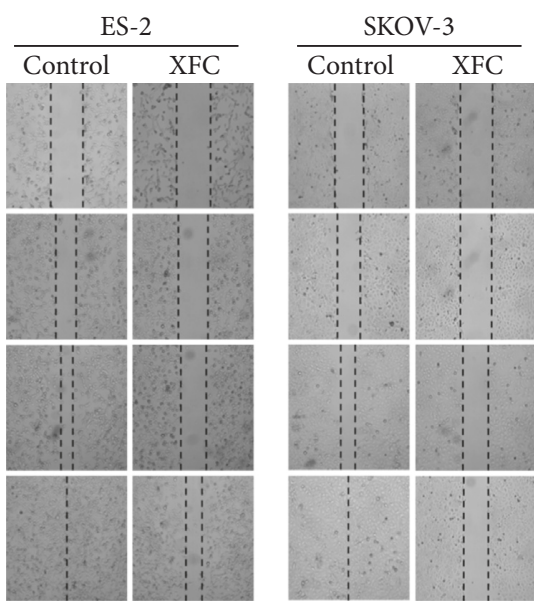

(a)
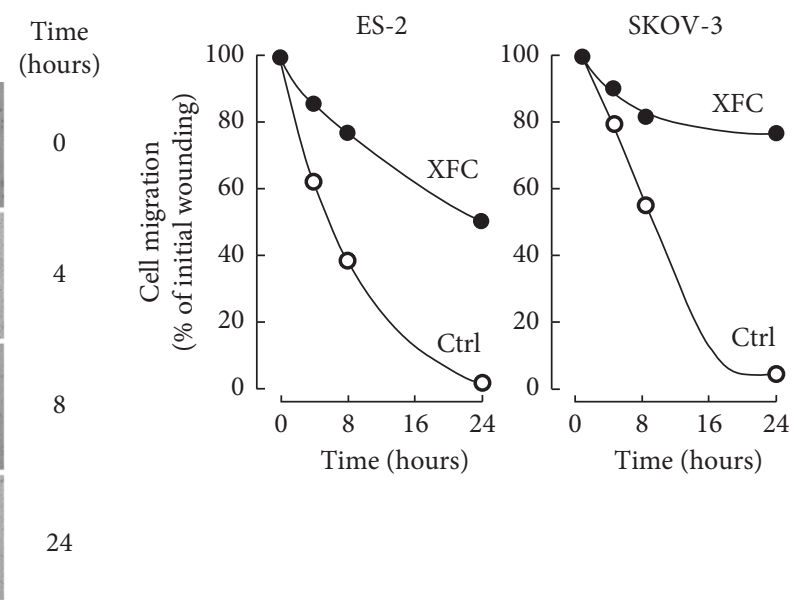

(b)

FIGURE 8: SKOV-3 ovarian cancer cells are resistant to the effect of XFC in a wound-healing assay. (a) Photomicrographs of ES-2 and SKOV-3 cell migration, in the presence or absence of $60 \mu \mathrm{g} / \mathrm{mL}$ XFC, to the scratched zone at different time points (magnification, $\times 20$ ). (b) Quantitative assessment of cells migrated into the scratched zone. For each condition, representative fields within the scratch were photographed. Data are representative of two independent experiments and are presented as a percentage of cell migration into the scratched zone in each culture medium group (control, 100\%).

Recurrence and therapy resistance following chemotherapy recently highlighted an integral role of ovarian cancer stem cells (CSC) [37]. Interest has risen in overcoming the therapeutic resistance phenotype conferred by ovarian CSC through the use of chemotherapeutic drugs in combination with metabolism targeting approaches [38]. 
Whether XFC or dietary-mediated intervention can also target ovarian CSC death remains to be explored. Evidence suggests that deregulation of key pro- and antiapoptotic pathways represents a key event in the acquisition and maintenance of ovarian cancer chemoresistance [39]. Among these, Survivin was recently identified as an antagonist of chemotherapy-induced cell death in colorectal cancer cells [40]. Furthermore, the discovery of novel interactions between apoptosis and necrosis pathways confirms that chemoresistance may be multifactorial. In our study, we provide evidence that XFC is able to trigger apoptosis in both sensitive (ES-2) and chemoresistant (SKOV3) ovarian cancer cells (Figures 2 and 3). Interestingly, significant XFC-mediated necrosis induction was only observed in SKOV-3 cells, suggesting that the ability of the ovarian cancer cell to escape the cytotoxic insult to XFC is a consequence of the overall necrotic balance response of that cell. Necrotic cell death mechanisms therefore appear to be preferentially involved in the chemoresistant SKOV-3 ovarian cell model (in contrast to ES- 2 cells where most of the cell death mechanism rather involve apoptosis). This differential cellular effect, which correlates with the chemoresistance molecular signature of SKOV-3 cells, reinforces the concept that profound impact of XFC is required to induce cell death and that such characteristics may explain the time frame and versatile capacity of its cytotoxic molecules content. Tentatively, short-term (24 hours) induction of both necrosis and apoptosis is triggered by $400 \mu \mathrm{g} / \mathrm{mL}$ XFC, and then switch from necrosis to late apoptosis completed upon long-term (48 hours) treatment.

Key proteins in cell cycle regulation, including c-myc, p21, Cdk4, and Cyclin D3, were all recently documented as potential prognostic factors in myoepithelial carcinoma of salivary glands [41]. Among the numerous target genes of MYC, Cdk4 and Cyclin D1 affect cell division since both regulate cell cycle progression and lead to enhanced proliferation [42]. Furthermore, Cdk inhibitors p15, p21, and p27 are downregulated by MYC, which impacts cell cycle progression in early and mid-G1 [42]. Our study highlights the capacity of XFC to specifically decrease Cdk4, Cyclin D3, and p27 expressions in chemoresistant SKOV-3 ovarian cancer cells (Figure 7(b)). This aspect is interesting as the formation of a ternary p27(kip1)/Cyclin D3/Cdk4 complex was recently described [43], and therapeutic targeting of the cyclin D3: CDK4/6 complex in T-cell leukemia envisioned as an efficient treatment for pediatric and adult T-cell leukemia where rapid cell cycle arrest in both mouse and human T-ALL cell lines was observed [44]. It is tempting to suggest that such similar targeting by XFC also takes place towards chemoresistant ovarian cancer cells. Moreover, XFC's ability to differentially target the microtubule dynamics and to further trigger necrosis events in that same model suggests that differential cell death decisions may be involved in line with the nature of the anticancer molecules content. The XFC-mediated mitotic arrest and increased necrosis that we observed in our SKOV-3 ovarian cancer cell model further appeared to be secondary to the accumulation of polymerized microtubules, in line with previously reported Taxol-induced transient mitotic arrest also associated with cell necrosis [45]. Finally, the caspase-independent apoptosis, triggered by the inhibition of cancer cell proliferation by berry juices, appeared similar to XFC treatments, to involve cell cycle arrest, as evidenced by downregulation in the expression of Cdk4, Cdk6, Cyclin D1, and Cyclin D3 in PC-3 prostate cancer cells [46]. Collectively, these data suggest that XFC contains anticancer molecules that could efficiently target crucial cell cycle division processes, which regulate chemoresistance. The closest antitumor impact and concentrations extrapolation one can perform at this point is provided from a recent study, which tested the in vivo antitumor impact of XFC to that of xanthatins fractionated from XFC in a colorectal xenograft model [47]. The authors elegantly demonstrated that daily administration for 15 days of $100 \mathrm{mg} / \mathrm{kg}$ XFC or of $5 \mathrm{mg} / \mathrm{kg}$ of xanthatins enriched fraction efficiently reduced tumor volumes to levels similar to that of a platinum chemotherapy drug at $6 \mathrm{mg} / \mathrm{kg}$ Oxaliplatin [47].

\section{Conclusion}

In conclusion, both of the cell death biochemical pathways believed to downregulate cell survival and the means by which XFC counteracts therapy resistance mechanisms still require more research. Our study provides the fundamental cellular mechanisms, which appear to be effectively targeted by XFC, and which may enable this treatment to circumvent some of the ovarian cancer cell chemoresistance mechanisms. Future perspectives should focus on identifying the exact active principles responsible for anticancer pharmacological activity. Furthermore, XFC impact on in vivo xenograft models may also be envisioned in small animal models and possibly administered in combination with current chemotherapy drugs.

\section{Data Availability}

The data used to support the findings of this study are available from the corresponding author upon request.

\section{Disclosure}

Partial presentation of the manuscript was done at the " 7 th International Symposium of Pharmaceutical Sciences VII SICF” (June 2019, Cayos de Villa Clara, Cuba). B. A. holds an Institutional UQAM Research Chair in Cancer Prevention and Treatment.

\section{Conflicts of Interest}

The authors declare that they have no conflicts of interest.

\section{Authors' Contributions}

J. P. F., S. L., and B. A. participated in research design; M. F. F., C. C., and M. L. G. conducted the experiments; M. L. G. prepared plant materials and extractions; M. F. F., J. P. F., S. L., and B. A. analyzed data and wrote or contributed to the writing of the manuscript. All the listed authors have read and approved the submitted manuscript. 


\section{Acknowledgments}

The authors thank Annie Levert and Denis Flipo for helpful technical assistance.

\section{References}

[1] J. S. Berek, "Epithelial ovarian cancer," in Practical Gynecologic Oncology, J. S. Berek and N. F. Hacker, Eds., p. 457, Lippincott Williams \& Wilkins, Philadelphia, PA, USA, 2000.

[2] K. Shen, "Chemotherapy in ovarian cancer," in Challenges and Controversies in Gynecologic Oncology, K. Shen and J. H. Lang, Eds., pp. 99-100, People's Medical Publishing House, Beijing, China, 2002.

[3] I. B. Roninson, J. E. Chin, K. G. Choi et al., "Isolation of human mdr DNA sequences amplified in multidrug-resistant KB carcinoma cells," Proceedings of the National Academy of Sciences, vol. 83, no. 12, pp. 4538-4542, 1986.

[4] R. D. H. Whelan, L. K. Hosking, A. J. Townsend, K. H. Cowan, and B. T. Hill, "Differential increases in glutathione S-transferase activities in a range of multidrug-resistant human tumor cell lines," Cancer Communications, vol. 1, no. 6, pp. 359-365, 1989.

[5] R. Brown, C. Clugston, A. Edlin et al., "Increased accumulation of p53 protein in cisplatin-resistant ovarian cell lines," International Journal of Cancer, vol. 55, no. 4, pp. 678-684, 1993.

[6] A. Vaisman, M. Varchenko, I. Said, and S. G. Chaney, "Cell cycle changes associated with formation of Pt-DNA adducts in human ovarian carcinoma cells with different cisplatin sensitivity," Cytometry, vol. 27, no. 1, pp. 54-64, 1997.

[7] S. Russi, H. K. Verma, S. Laurino et al., "Adapting and surviving: intra and extra-cellular remodeling in drug-resistant gastric cancer cells," International Journal of Molecular Sciences, vol. 20, no. 15, p. 3736, 2019.

[8] X. D. Yan, M. Li, Y. Yuan, N. Mao, and L. Y. Pan, "Biological comparison of ovarian cancer resistant cell lines to cisplatin and Taxol by two different administrations," Oncology Reports, vol. 17, no. 5, pp. 1163-1169, 2007.

[9] N. S. Wind and I. Holen, "Multidrug resistance in breast cancer: from in vitro models to clinical studies," International Journal of Breast Cancer, vol. 2011, Article ID 967419, 12 pages, 2011.

[10] G. M. Cragg and D. J. Newman, "Natural products: a continuing source of novel drug leads," Biochimica et Biophysica Acta (BBA)_General Subjects, vol. 1830, no. 6, pp. 3670-3695, 2013.

[11] A. Kamboj and A. Saluja, "Phytopharmacological review of Xanthium strumarium L. (Cocklebur)," International Journal of Green Pharmacy, vol. 4, no. 3, pp. 129-139, 2010.

[12] B. Lin, Y. Zhao, P. Han et al., "Anti-arthritic activity of Xanthium strumarium L. extract on complete Freund's adjuvant induced arthritis in rats," Journal of Ethnopharmacology, vol. 155, no. 1, pp. 248-255, 2014.

[13] H. S. Kim, T. S. Lee, S. W. Yeo, L. S. Seong, and T. S. Yu, "Isolation and characterization of antitumor agents from Xanthium strumarium L.," Korean Society for Biotechnology and Bioengineering Journal, vol. 18, pp. 324-328, 2003.

[14] A. Kovács, A. Vasas, P. Forgo, B. Réthy, I. Zupkó, and J. Hohmann, "Xanthanolides with antitumour activity from Xanthium italicum," Zeitschrift für Naturforschung C, vol. 64, no. 5-6, pp. 343-349, 2009.

[15] I. Ramírez-Erosa, Y. Huang, R. A. Hickie, R. G. Sutherland, and B. Barl, "Xanthatin and xanthinosin from the burs of
Xanthium strumarium L. as potential anticancer agents," Canadian Journal of Physiology and Pharmacology, vol. 85, no. 11, pp. 1160-1172, 2007.

[16] A. Vasas and J. Hohmann, "Xanthane sesquiterpenoids: structure, synthesis and biological activity," Natural Product Reports, vol. 28, no. 4, pp. 824-842, 2011.

[17] J. Piloto Ferrer, R. Cozzi, T. Cornetta et al., "Xanthium strumarium L. extracts produce DNA damage mediated by cytotoxicity in in vitro assays but does not induce micronucleus in mice," BioMed Research International, vol. 2014, Article ID 575197, 8 pages, 2014.

[18] A. Sánchez-Lamar, J. Piloto-Ferrer, M. Fiore et al., "Xanthium strumarium extract inhibits mammalian cell proliferation through mitotic spindle disruption mediated by xanthatin," Journal of Ethnopharmacology, vol. 194, pp. 781-788, 2016.

[19] T. Mosmann, "Rapid colorimetric assay for cellular growth and survival: application to proliferation and cytotoxicity assays," Journal of Immunological Methods, vol. 65, no. 1-2, pp. 55-63, 1983.

[20] C.-C. Liang, A. Y. Park, and J.-L. Guan, "In vitro scratch assay: a convenient and inexpensive method for analysis of cell migration in vitro," Nature Protocols, vol. 2, no. 2, pp. 329333, 2007.

[21] E. A. Perez, "Microtubule inhibitors: differentiating tubulininhibiting agents based on mechanisms of action, clinical activity, and resistance," Molecular Cancer Therapeutics, vol. 8, no. 8, pp. 2086-2095, 2009.

[22] G. S. Menon, K. Kuchroo, and D. Dasgupta, "Interaction of microtubules with active principles of Xanthium strumarium," Physiological Chemistry and Physics and Medical NMR, vol. 33, no. 2, pp. 153-162, 2001.

[23] D. C. Guzmán-Ocampo, R. Aguayo-Ortiz, L. Cano-González, R. Castillo, A. Hernández-Campos, and L. Dominguez, "Effects of the protonation state of titratable residues and the presence of water molecules on nocodazole binding to $\beta$-tubulin," ChemMedChem, vol. 13, no. 1, pp. 20-24, 2018.

[24] Q. Ma, "Role of nrf2 in oxidative stress and toxicity," Annual Review of Pharmacology and Toxicology, vol. 53, no. 1, pp. 401-426, 2013.

[25] M. Iranshahy, M. Iranshahi, S. R. Abtahi, and G. Karimi, "The role of nuclear factor erythroid 2-related factor 2 in hepatoprotective activity of natural products: a review," Food and Chemical Toxicology, vol. 120, pp. 261-276, 2018.

[26] A. Vidal and A. Koff, "Cell-cycle inhibitors: three families united by a common cause," Gene, vol. 247 , no. 1-2, pp. 1-15, 2000.

[27] C. Hills, L. Kelland, G. Abel, J. Siracky, A. Wilson, and K. Harrap, "Biological properties of ten human ovarian carcinoma cell lines: calibration in vitro against four platinum complexes," British Journal of Cancer, vol. 59, no. 4, pp. 527-534, 1989.

[28] D.-H. Lee, M. Szczepanski, Y. J. Lee, D. H. Lee, M. Szczepanski, and Y. J. Lee, "Role of bax in quercetin-induced apoptosis in human prostate cancer cells," Biochemical Pharmacology, vol. 75, no. 12, pp. 2345-2355, 2008.

[29] A. M. Wong, Y. Zhang, K. Kesler et al., "Genomic and in vivo evidence of synergy of a herbal extract compared to its most active ingredient: rabdosia rubescens vs. oridonin," Experimental and Therapeutic Medicine, vol. 1, no. 6, pp. 1013-1017, 2010.

[30] N. P. Seeram, L. S. Adams, M. L. Hardy, and D. Heber, "Total cranberry extract versus its phytochemical constituents: antiproliferative and synergistic effects against human tumor 
cell lines," Journal of Agricultural and Food Chemistry, vol. 52, no. 9, pp. 2512-2517, 2004.

[31] F. A. Al-Mekhlafi, N. Abutaha, A. M. A. Mashaly, F. A. Nasr, K. E. Ibrahim, and M. A. Wadaan, "Biological activity of Xanthium strumarium seed extracts on different cancer cell lines and Aedes caspius, Culex pipiens (diptera: Culicidae)," Saudi Journal of Biological Sciences, vol. 24, no. 4, pp. 817-821, 2017.

[32] R. I. Geran, N. H. Greenberg, M. M. Macdonald, A. M. Shumacher, and B. J. Abbott, "Protocols for screening chemical agents and natural products against animal tumors and other biological systems," Cancer Chemotherapy Reports, vol. 3, no. 2, pp. 100-103, 1972.

[33] S. Xie and J. Zhou, "Harnessing plant biodiversity for the discovery of novel anticancer drugs targeting microtubules," Frontiers in Plant Science, vol. 8, p. 720, 2017.

[34] D. Bates and A. Eastman, "Microtubule destabilising agents: far more than just antimitotic anticancer drugs," British Journal of Clinical Pharmacology, vol. 83, no. 2, pp. 255-268, 2017.

[35] C. L. Rieder and H. Maiato, "Stuck in division or passing through: what happens when cells cannot satisfy the spindle assembly checkpoint," Developmental Cell, vol. 7, no. 5, pp. 637-651, 2004.

[36] J. Benada and L. Macurek, "Targeting the checkpoint to kill cancer cells," Biomolecules, vol. 5, no. 3, pp. 1912-1937, 2015.

[37] C. L. W. Haygood, R. C. Arend, J. M. Straughn, and D. J. Buchsbaum, "Ovarian cancer stem cells: can targeted therapy lead to improved progression-free survival?," World Journal of Stem Cells, vol. 6, no. 4, pp. 441-447, 2014.

[38] S.-S. Li, J. Ma, and A. S. T. Wong, "Chemoresistance in ovarian cancer: exploiting cancer stem cell metabolism," Journal of Gynecologic Oncology, vol. 29, no. 2, p. e32, 2018.

[39] M. Fraser, B. Leung, A. Jahani-Asl, X. Yan, W. E. Thompson, and B. K. Tsang, "Chemoresistance in human ovarian cancer: the role of apoptotic regulators," Reproductive Biology and Endocrinology, vol. 1, no. 1, p. 66, 2003.

[40] A. Rauch, A. Carlstedt, C. Emmerich et al., "Survivin antagonizes chemotherapy-induced cell death of colorectal cancer cells," Oncotarget, vol. 9, no. 45, pp. 27835-27850, 2018.

[41] F. Passador-Santos, M. Grönroos, J. Irish et al., "Clinicopathological characteristics and cell cycle proteins as potential prognostic factors in myoepithelial carcinoma of salivary glands," Virchows Archiv, vol. 468, no. 3, pp. 305-312, 2016.

[42] R. Weinberg, "pRB and control of the cell cycle clock,", in The Biology of Cancer, R. Weinberg, Ed., pp. 255-306, Garland Science, New York, NY, USA, 1st edition, 2007.

[43] F. Dong, D. Agrawal, T. Bagui, and W. J. Pledger, "Cyclin D3associated kinase activity is regulated by p27kip1 in BALB/c 3T3 cells," Molecular Biology of the Cell, vol. 9, no. 8, pp. 2081-2092, 1998.

[44] C. M. Sawai, J. Freund, P. Oh et al., "Therapeutic targeting of the cyclin D3:CDK4/6 complex in T cell leukemia," Cancer Cell, vol. 22, no. 4, pp. 452-465, 2012.

[45] R. H. Hruban, J. H. Yardley, R. C. Donehower, and J. K. Boitnott, "Taxol toxicity. Epithelial necrosis in the gastrointestinal tract associated with polymerized microtubule accumulation and mitotic arrest," Cancer, vol. 63, no. 10, pp. 1944-1950, 1989.

[46] D. Boivin, M. Blanchette, S. Barrette, A. Moghrabi, and R. Béliveau, "Inhibition of cancer cell proliferation and suppression of TNF-induced activation of NFkappaB by edible berry juice," Anticancer Research, vol. 27, no. 2, pp. 937-948, 2007.

[47] J. Piloto-Ferrer, Á. Sánchez-Lamar, M. Francisco et al., "Xanthium strumarium's xanthatins induces mitotic arrest and apoptosis in CT26WT colon carcinoma cells," Phytomedicine, vol. 57, pp. 236-244, 2019. 


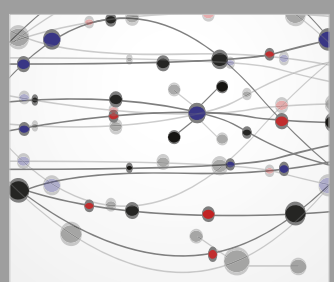

The Scientific World Journal
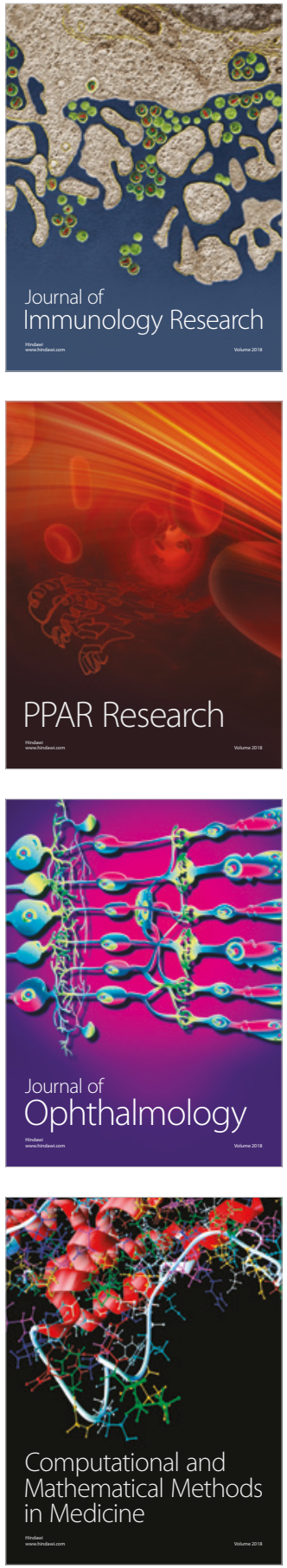

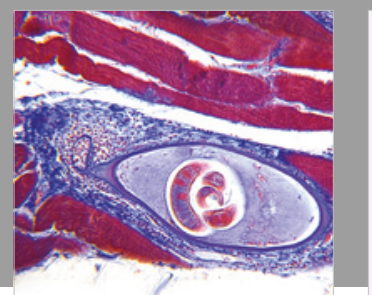

Gastroenterology Research and Practice

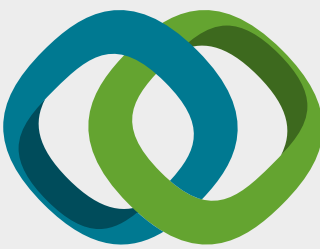

\section{Hindawi}

Submit your manuscripts at

www.hindawi.com
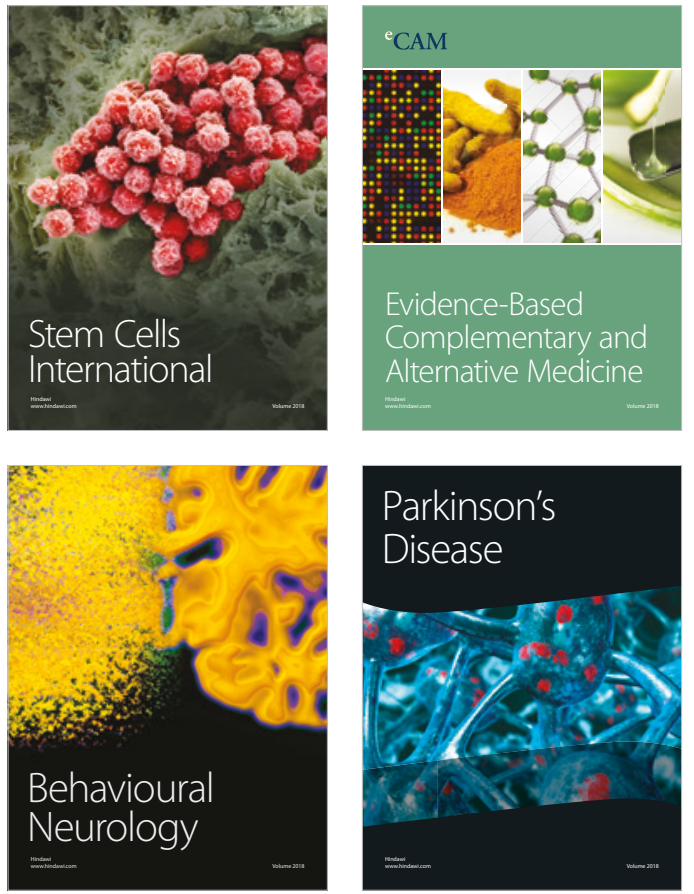

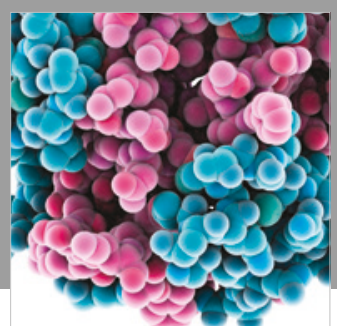

ournal of

Diabetes Research

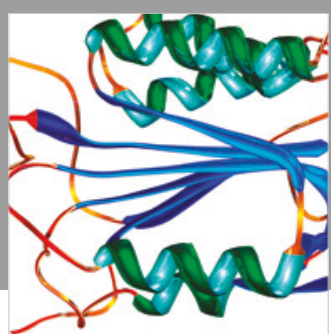

Disease Markers
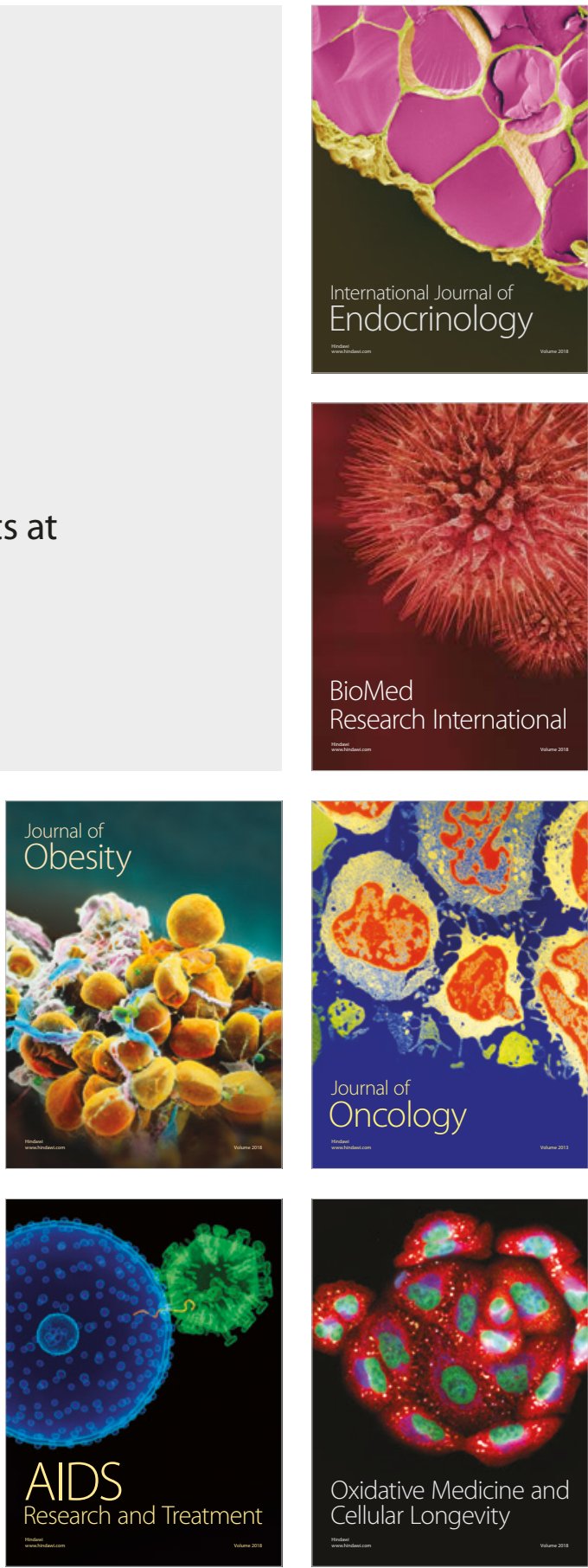